\title{
Numerical modelling of heat convection processes in the ducts of two-stage heat exchanger
}

\author{
Zhivko Kolev ${ }^{1,}{ }^{*}$ and Seher Kadirova ${ }^{2}$ \\ ${ }^{1}$ Department of Heat, Hydraulics and Environmental Engineering, University of Ruse, Ruse 7017, \\ Bulgaria \\ ${ }^{2}$ Department of Electronics, University of Ruse, Ruse 7017, Bulgaria
}

\begin{abstract}
The paper presents results from numerical modelling in ABAQUS of heat convection processes in the ducts of two-stage "water to air" heat exchanger, used as a heat consumer in reversible heat pump installation. A comparison between the values of heat convection coefficient has been done, as they have been determined on the basis of simulation results, and criterion equations. The heat convection processes have been modelled on the base of boundary conditions, determined by measuring of main parameters. The computing mesh has been verified on the basis of certain temperature values, by successively increasing the number of computing cells. The heat convection processes in the ducts of the heat exchanger have been simulated in "heating" and "cooling" modes of the installation. The study has been performed in laboratory conditions.
\end{abstract}

\section{Introduction}

In heat exchangers, the processes of heat transfer at forced convection are very common and are the subject of many studies and calculations. An experimental study of a crosscurrent heat exchanger is presented in [1]. The heat flows, heat convection coefficients and overall heat transfer coefficients, have been calculated. The research [2] focuses on the experimental determination of dependencies between certain criterion parameters, used for calculations of a heat exchanger with spirally finned tubes. In [3] is presented the methodology of experimental determination of heat convection coefficients and heat flows in a two-pipe heat exchanger. A tube-in-tube heat exchanger is studied in [4]. The main relations between different criterion parameters have been determined. Investigation [5] presents calculation of thermal and hydraulic parameters of a heat exchanger with wavy finned surfaces. In [6] a methodology for investigation of the hydrodynamics of a floating head heat exchanger is presented. Article [7] focuses on an experimental study of a heat exchanger used in an air-conditioning system. The heat flows exchanged under operation of the installation in "heating" mode, have been calculated.

One of the most common methods for studying various heat transfer and hydrodynamic processes is the numerical modelling. For this purpose, various computer programs and

* Corresponding author: zkolev@uni-ruse.bg 
approaches are used. In investigation [8] is presented the numerical modelling in ANSYS of heat transfer processes in pipes with different finning. In another research a computer simulation in ANSYS of processes of convective heat transfer in pipes with different possibilities for turbulisation of the fluid flowing in them, is considered [9]. Paper [10] focuses on simulation of heat transfer processes in tubes with internal finning in the simulation environment ANSYS. Article [11] presents computer modelling in COMSOL Multiphysics of thermal conductivity processes in a finned tube heat exchanger. In [12] a mathematical modelling of thermal conductivity processes in the fins of a heat exchange apparatus operating according to the "cross-flow" scheme is considered. Paper [13] focuses on computer modelling in COMSOL Multiphysics of processes in a finned-tube heat exchanger. Investigation [14] presents a mathematical modelling of a heat exchanger with finned tubes, applied in drying processes. Another approach of computer modelling in ANSYS of heat transfer processes in the fins of a heat exchanger used in road vehicles is presented in [15]. Article [16] focuses on computer simulation of the temperature field in the walls of buildings. Study [17] presents numerical modelling of the temperature distribution in samples of building thermal insulation materials. In [18] a mathematical modelling of the heat transfer process at the movement of fluid in a pipe is considered. Paper [19] discusses computer simulation in ANSYS of processes of mixing fluids with different temperatures. Investigation [20] presents a numerical simulation of the temperature field around gas pores in the structure of samples made by synthetic materials. In [21], a computer simulation in ANSYS of the velocity distribution of a fluid passing through a cone diffuser is presented. Paper [22] has proposed a mathematical model of the induction heating process of cylindrical pieces. Study [23] presents numerical modelling based on finite difference method of the thermal conditions of a LED driver.

The efficiency of heat consumers, representing various heat exchangers, has a significant importance in heat pump installations. The efficiency of these installations is also influenced by the parameters of the environment, as presented in [24].

This paper presents results from investigation the processes of heat convection in the ducts of a two-stage "water to air" heat exchanger, used as a heat consumer in a reversible heat pump installation. A comparison between the values of the heat convection coefficients, determined by numerical modelling of the processes in ABAQUS, and on the basis of criterion equations, has been performed.

\section{Methodology}

The investigation has been realized in order to design a new heat exchanger.

Figure 1 presents a block diagram of the heat pump installation. The heat pump is reversible, which allows research to be performed in "summer" and "winter" modes. Water buffer is used as the heat source. The heat consumer is a two-stage "water to air" heat exchanger (HE). In order to maintain a constant temperature of the water coming from the buffer into the heat pump, the stratification conditions in the buffer have been met. The block diagram in Fig. 1 presents valve positions of the system at investigation in "cooling" mode. 


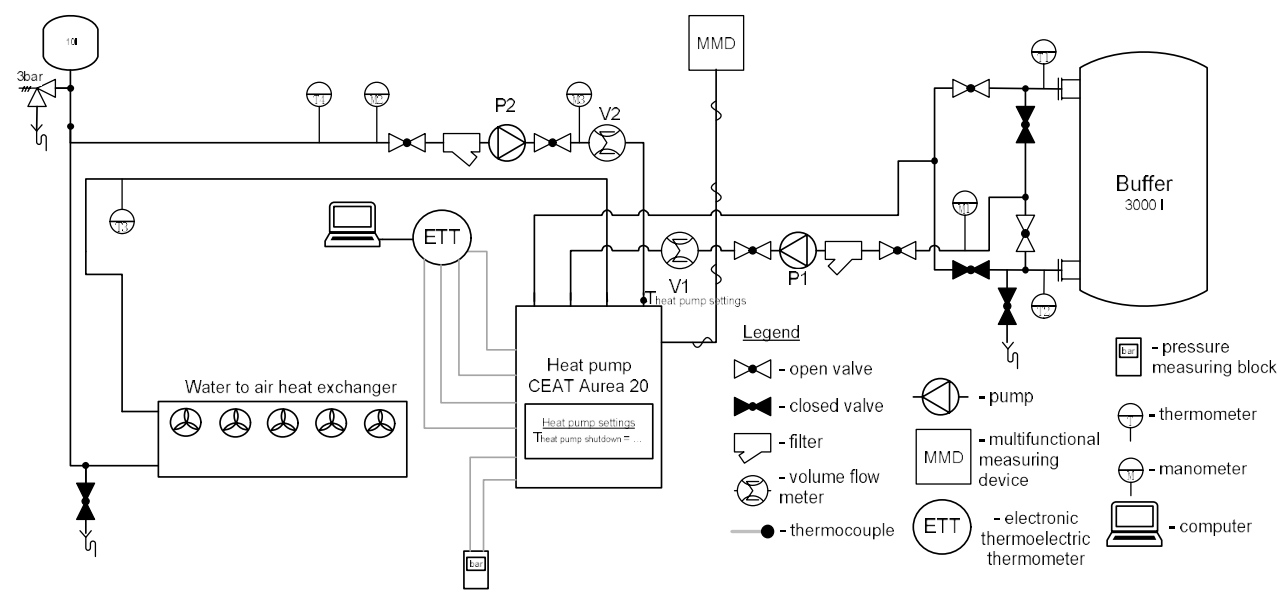

Fig. 1. Block diagram of heat pump installation.

Figure 2 presents a diagram of the "water to air" heat exchanger. The basic geometrical parameters in $\mathrm{mm}$, necessary for implementation the thermal calculations of the apparatus, have been presented.
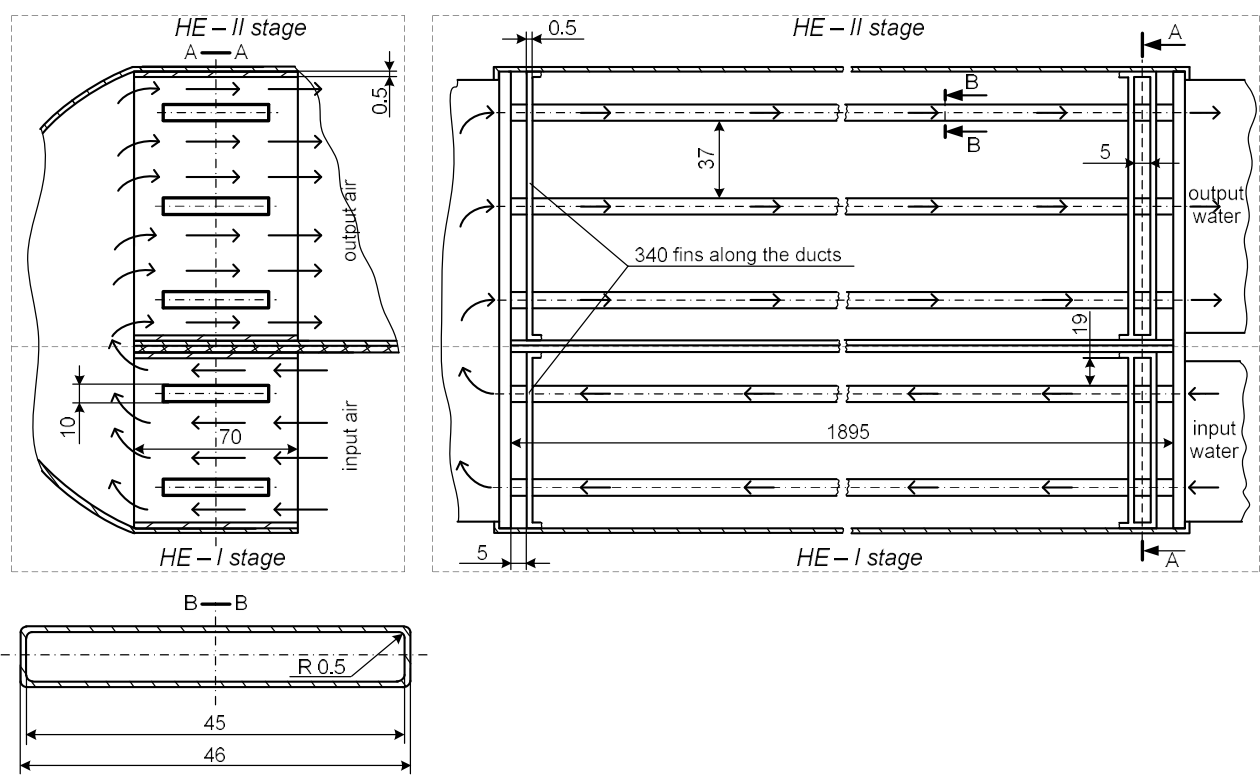

Fig. 2. A diagram of the heat exchanger.

The following equations have been used for calculation of the internal heat convection coefficients, by simulation of the heat transfer processes:

$$
\begin{aligned}
& \bar{h}_{c, 1-\text { simulation }}=\frac{Q_{1-\text { duct-heating }}}{A_{1-\text { int ermal }} \Delta \bar{T}_{1-\text { int ernal }}} \\
& \bar{h}_{c, 1-\text { simulation }}=\frac{Q_{1-\text { duct-cooling }}}{A_{1-\text { intermal }} \Delta \bar{T}_{1-\text { int ernal }}}
\end{aligned}
$$


where: $Q_{1-\text { duct-heating }}$ is the heat flow, exchanged between the water flowing in a duct from the heat exchanger, and its internal heat exchange surface, at "heating" mode of the installation, $\mathrm{W}$;

$Q_{1-\text { duct-cooling }}$ - heat flow at "heating" mode, W;

$A_{1-\text { internal }}$ - the internal heat exchange surface area of one duct, $\mathrm{m}^{2}$;

$\Delta \bar{T}_{1-i n t e r m a l}$ - average cross-section temperature difference of the duct, K.

The heat flows $Q_{1-\text { duct-heating }}$ and $Q_{1 \text {-duct-cooling }}$ have been calculated by the basic heat equation.

The average temperature difference $\Delta \bar{T}_{1 \text {-intermal }}$ have been determined based on the simulated temperature field of the fluid, flowing in the duct. For this purpose, the computing mesh of the model has been verified on the basis of certain temperature values, by successively increasing the number of computing cells. The investigation has been accomplished in ABAQUS software environment.

For determination of the heat convection coefficients $\bar{h}_{c, 1-c r i t r i o n e q u a t i o n}$ by the criterion method, one of the following two criterion equations has been used, depending on the value of the obtained Reynolds number:

$$
\begin{gathered}
N u_{f d, 1}=0.008 \operatorname{Re}_{f d, 1}^{0.9} \operatorname{Pr}_{f, 1}^{0.43} \\
N u_{f d, 1}=1.4\left(\operatorname{Re}_{f d, 1} \frac{d_{\text {equiv.-duct }}}{L_{\text {duct }}}\right)^{0.4} \operatorname{Pr}_{f, 1}^{0.33}\left(\frac{P r_{f, 1}}{P r_{w, 1}}\right)^{0.25}
\end{gathered}
$$

$d_{\text {equiv-duct }}$ is the equivalent internal diameter of the duct, $\mathrm{m}$.

$L_{\text {duct }}$ is the length of each duct from the heat exchanger, $\mathrm{m}$.

The equivalent internal diameter has been calculated by the equation:

$$
d_{\text {equiv. duct }}=\frac{4 f_{\text {duct }}}{P_{\text {duct }}}
$$

where: $f_{\text {duct }}$ is the area of the internal cross-section of the duct, $\mathrm{m}^{2}$;

$P_{\text {duct }}$ - perimeter of the cross-section, $\mathrm{m}$.

The comparison between the heat convection coefficients, determined by the presented two methods, is done by calculating the percentage difference between them, according to the following equation:

$$
\text { Percentage Difference }=\frac{\left|\bar{h}_{c, 1-\text { simulation }}-\bar{h}_{c, 1 \text {-criterion equation }}\right|}{\frac{\bar{h}_{c, 1-\text { simulation }}+\bar{h}_{c, 1-\text { criterion equation }}}{2}} 100
$$

\section{Results and discussion}

Table 1 presents the values of the boundary conditions used for computer simulation of the heat transfer processes. The boundary conditions are as follows: bulk fluid temperature of the duct input $T_{f, 1-\text { input }}$, bulk fluid temperature of the duct output $T_{f, 1-\text { output }}$, fluid velocity in 
the input cross-section of the duct $U_{1-i n p u t}$, manometric pressure of the fluid in the output cross-section of the duct $p_{m, 1-\text { output }}$, heat flux in the duct $q_{1-\text { duct }}$.

Table 1. Boundary conditions for simulation of heat transfer processes.

\begin{tabular}{|c|c|c|c|c|c|}
\hline $\begin{array}{c}\text { Heat } \\
\text { transfer } \\
\text { process }\end{array}$ & $\mathbf{T}_{\mathrm{f}, 1 \text {-input, }}{ }^{0} \mathrm{C}$ & $\mathbf{T}_{f, 1-\text { output }},{ }^{\circ} \mathrm{C}$ & $\mathbf{U}_{1 \text {-input }}, \mathbf{m} / \mathbf{s}$ & $\mathbf{p}_{\mathrm{m}, 1-\mathrm{output}}, \mathbf{P a}$ & $\mathbf{q}_{1 \text {-duct, }}, W / \mathbf{m}^{2}$ \\
\hline $\begin{array}{l}\text { HE - I stage } \\
\text { "Cooling" } \\
\text { mode }\end{array}$ & 9.9 & 11.9 & 0.216 & 90070 & 3577.91 \\
\hline $\begin{array}{l}\mathrm{HE} \text { - II stage } \\
\text { "Cooling" } \\
\text { mode }\end{array}$ & 11.9 & 12.8 & 0.144 & 90000 & 1073.17 \\
\hline $\begin{array}{l}\text { HE - I stage } \\
\text { "Heating" } \\
\text { mode }\end{array}$ & 51.1 & 47.5 & 0.218 & 90050 & 6415.37 \\
\hline $\begin{array}{c}\mathrm{HE}-\text { II stage } \\
\text { "Heating" } \\
\text { mode }\end{array}$ & 47.5 & 44.6 & 0.145 & 90000 & 3445.29 \\
\hline
\end{tabular}

The used shape of the computing cells for simulation of the heat convection processes is "Tet". The verification of the computing mesh has been performed on the base of temperature results of a node, located at the output duct's cross-section. The selected mesh is with cells' size of $0.007 \mathrm{~m}$.

Table 2 presents the obtained values of the heat convection coefficients and the percentage difference between them by apply of the two presented methods.

Table 2. Results for heat convection coefficients.

\begin{tabular}{|c|c|c|c|}
\hline $\begin{array}{c}\text { Heat transfer } \\
\text { process }\end{array}$ & $\begin{array}{c}\overline{\mathbf{h}}_{\mathbf{c}, 1-\text { simulation }}, \\
\mathbf{W} /\left(\mathbf{m}^{2} \mathbf{K}\right)\end{array}$ & $\begin{array}{c}\overline{\mathbf{h}}_{\mathbf{c}, 1 \text {-criterionequation }}, \\
\mathbf{W} /\left(\mathbf{m}^{\mathbf{2}} \mathbf{K}\right)\end{array}$ & $\begin{array}{c}\text { Percentage } \\
\text { Difference, } \%\end{array}$ \\
\hline $\begin{array}{c}\text { HE - I stage } \\
\text { "Cooling" mode }\end{array}$ & 553.92 & 933.42 & 51.03 \\
\hline $\begin{array}{c}\text { HE - II stage } \\
\text { "Cooling" mode }\end{array}$ & 480.06 & 267.88 & 56.74 \\
\hline $\begin{array}{c}\text { HE - I stage } \\
\text { "Heating" mode }\end{array}$ & 1058.93 & 1534.69 & 36.69 \\
\hline $\begin{array}{c}\text { HE - II stage } \\
\text { "Heating" mode }\end{array}$ & 853.23 & 983.07 & 14.14 \\
\hline
\end{tabular}

The heat convection coefficient $\bar{h}_{c, 1-c r i t e r i o n e q u a t i o n}$ at HE - II stage, "cooling" mode, is determined on the basis of criterion equation (4). For determination the heat convection coefficients by the criterion method for the other three heat transfer processes, criterion equation (3) have been used.

It should be noted that the way of calculation of the determinative size of the heat exchange surface $d_{\text {equiv.duct }}$ influences the determination of the heat convection coefficients, based on criterion equations. It is included in the equations for calculation of Reynolds number, in a separate expression in criterion equation (4), as well as in the equation for calculation of the heat convection coefficient, based on Nusselt number. The equivalent internal diameter $d_{\text {equiv-duct }}$ is calculated by equation (5) which is valid for ducts with an arbitrary cross-sectional shape. This equation does not express the specific features 
of the investigated duct cross-section. This affects the accuracy of determining the heat convection coefficients by this method.

From the results presented in Table 2 can be concluded that in general the higher values of heat convection coefficients are obtained in "heating" mode, comparing to "cooling" mode. This is due to the set operating parameters of the heat pump, as well as the ambient temperature in the relevant experimental investigations.

It can be noted that in the first stage of the heat exchanger, the heat convection coefficients have higher values compared to the second stage. The reason for this is the temperature variation of the airflow, passing through the first stage of the heat exchanger, which leads to a smaller temperature difference in the second stage.

In "heating" mode, the percentage difference between the heat convection coefficients determined by the two methods is lower than in "cooling" mode.

Figure 3 presents the simulated temperature distribution and the simulated fluid velocity distribution in the central cross-section of the heat exchanger ducts.

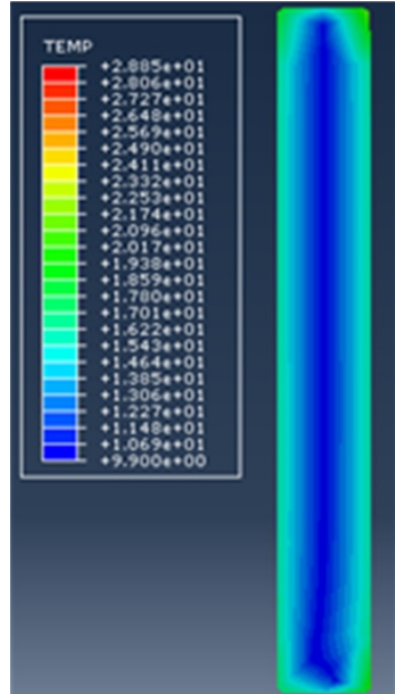

Temperature distribution HE - I stage

"Cooling" mode

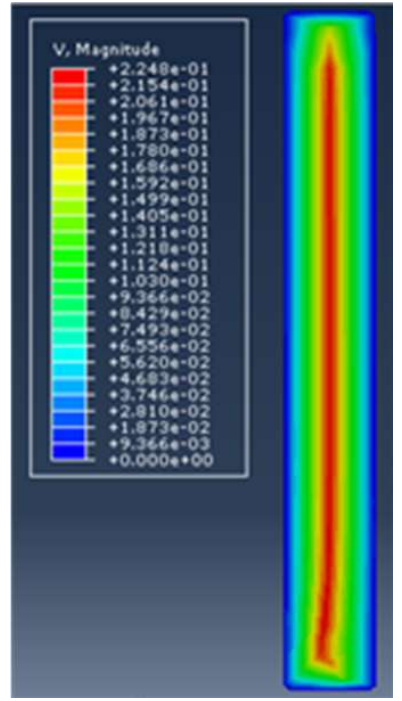

Velocity distribution HE - I stage "Cooling" mode 


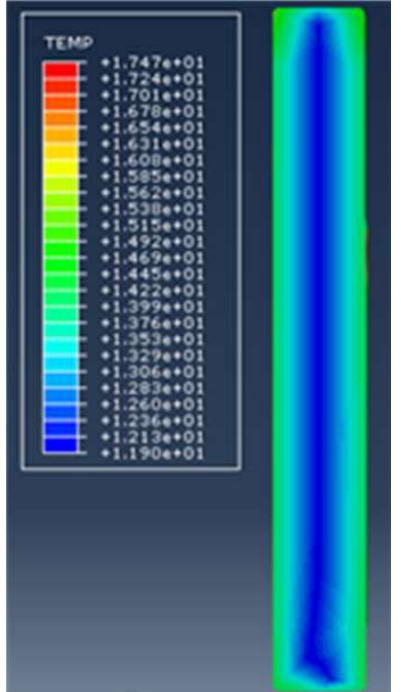

Temperature distribution HE - II stage "Cooling" mode

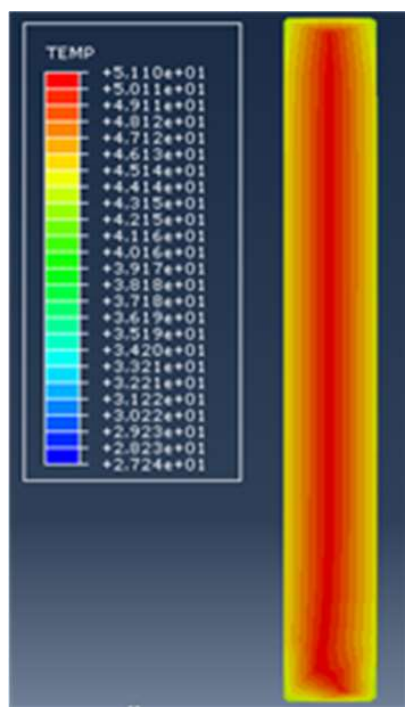

Temperature distribution HE - I stage

"Heating" mode

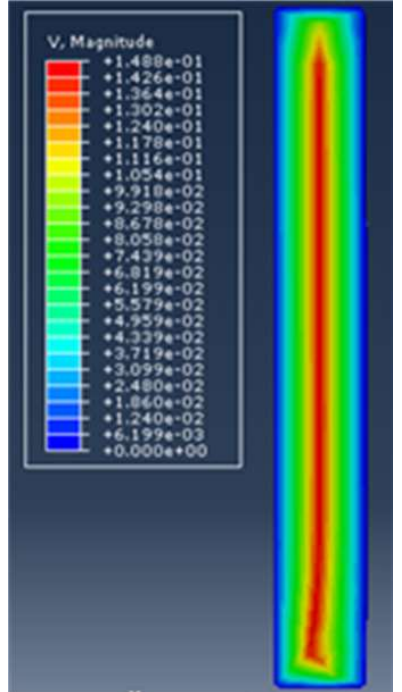

Velocity distribution HE - II stage "Cooling" mode

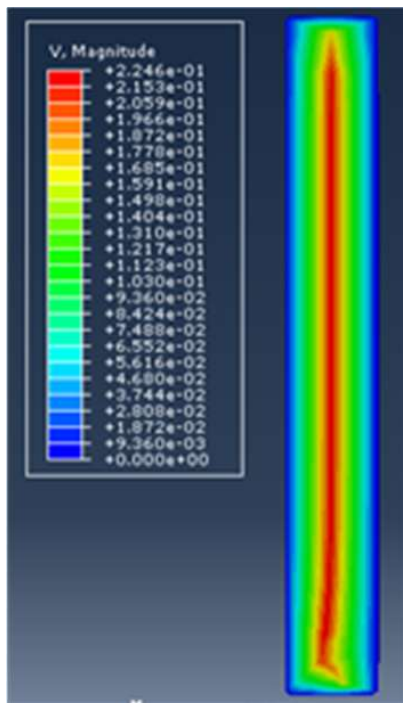

Velocity distribution HE - I stage

"Heating" mode 


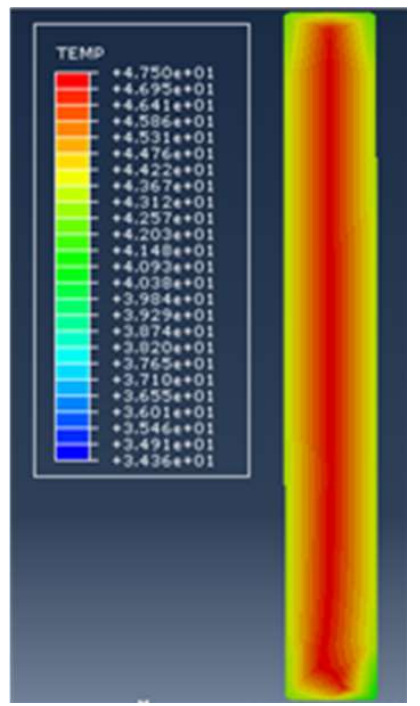

Temperature distribution HE - II stage

"Heating" mode

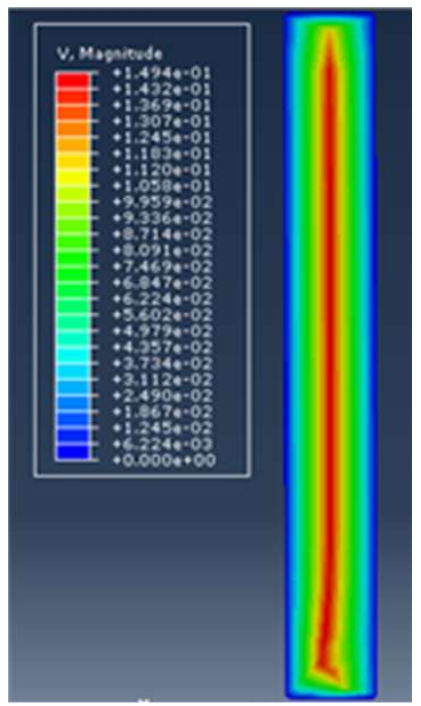

Velocity distribution

HE - II stage

"Heating" mode

Fig. 3. Simulation results for the temperature distribution and the fluid velocity distribution in the ducts' central cross-section.

The results presented in Figure 3 are used for determination of the heat convection coefficients by the method of simulation of the heat transfer processes in the ducts. From the simulation data for the temperature distribution of the fluid, it can be seen that the change in temperature near the internal surface of the duct is more significant. The results for the distribution of the fluid velocity present that near the internal surface of the duct the velocity has relatively low values, which is due to the higher forces of internal friction.

The influence of the specific shape and the geometric parameters of the ducts on the fluid temperature field has been noticed. This affects the values of the average temperature difference in cross-section, and respectively the values of the heat convection coefficients, calculated by equations (1) and (2).

In subsequent studies, the simulation results obtained for the temperature distribution on the internal surface of the ducts can be compared with experimental results. For this purpose, it is necessary to measure the temperature at certain points on the external surface, and the thermal resistance in the ducts' walls must be neglected.

\section{Conclusion}

Simulation results for the temperature and the velocity distribution of the fluid flowing in the ducts of heat exchanger have been obtained.

A methodology for determination of the heat convection coefficients in the heat exchanger ducts by using simulation data has been proposed.

Heat convection coefficients have been determined on the basis of simulation of the heat transfer processes and on the basis of criterion equations.

The percentage difference between the coefficients determined by the two methods has been calculated. According to the obtained results, the highest percentage difference between the coefficients is observed in the second stage of the heat exchanger, when the installation is operating in "cooling" mode. The lowest percentage difference is in the same stage of the apparatus, but in "heating" mode. 
The influence of the method of calculation of the determinative size of the heat exchange surface on the accuracy of determining the heat convection coefficients by the presented criterion equations has been analyzed.

The influence of the investigation conditions including the system parameters and the environment parameters, and the variation of airflow parameters on the heat convection coefficients have been analyzed. A comparative analyze has been accomplished regarding the heat convection coefficient values in the two stages of the heat exchanger, and in the two modes of operation of the heat pump installation.

\section{References}

1. Z. Kadhim, M. Kassim, A. Hassan, Effect of integral finned tube on heat transfer characteristics for cross flow heat exchanger, International Journal of Computer Applications (0975 - 8887), 139 (2016)

2. He Fa Jiang, Cao Wei Wu, Yan Ping, Experimental investigation of heat transfer and flowing resistance for air flow cross over spiral finned tube heat exchanger, Energy Procedia 17, 741 (2012)

3. M.S. Baba, M. Bhagvanth Rao, A. V. Sita Rama Raju, Experimental study of convective heat transfer in a finned tube counter flow heat exchanger with $\mathrm{Fe}_{3} \mathrm{O}_{4}-$ water nanofluid, International Journal of Mechanical Engineering and Technology (IJMET), 500 (2017)

4. A.H. Dhumal, G.M. Kerkal, K.T. Pawale, Heat transfer enhancement for tube in tube heat exchanger using twisted tape inserts, IJAERS 4, 89 (2017)

5. S. Albetel, A. Rus, E. David, V. Martian, The amplitude influence on the thermal and hydraulic performances for a wavy air fin in a compact heat exchanger used in agriculture applications, E3S Web of Conferences 180, 01006, TE-RE-RD, (2020)

6. S. Tasheva, Z. Hodjeva, V. Rasheva, G. Valtchev, B. Milenkov, Investigation of the hydrodynamics of a floating head heat exchanger, Heat Engineering 2 (5), 11, (2013)

7. S. Valchev, I. Mihaylov, Analysis of energy efficiency of air handling unit with integrated air to air heat exchanger in heating mode, E3S Web of Conferences 207, PEPM, 01002 (2020)

8. M. Zaidan, A. Alkumait, T. Ibrahim, Assessment of heat transfer and fluid flow characteristics within finned flat tube, Case Studies in Thermal Engineering 12, 557 (2018)

9. W. Osley, P. Droegemueller, P. Ellerby, CFD Investigation of Heat Transfer and Flow Patterns in Tube Side Laminar Flow and the Potential for Enhancement, Chem. Eng. Trans. J. 35, 997 (2013)

10. K. Majewski, S. Grądziel, CFD Simulations of Heat Transfer in Internally Helically Ribbed Tubes, Chem. Process Eng. J. 37 (2), 251 (2016)

11. S. Singh, K. Sørensen, T. Condra, Multiphysics numerical modeling of a fin and tube heat exchanger, Proceedings of the 56th SIMS, 383 (2015)

12. D. Jung, D. N. Assanis, Numerical modeling of cross flow compact heat exchanger with louvered fins using thermal resistance concept, SAE Technical Paper Series, (2006)

13. S. Arena, E. Casti, J. Gasia, L. F. Cabeza, G. Cau, Numerical simulation of a finnedtube LHTES system: influence of the mushy zone constant on a phase change behavior, Energy Procedia 126 (201709), 517 (2017) 
14. Lin Wei, Guorong Zhu, Zhijiang Jin, Numerical simulation of heat transfer in finned tube of heat recovery unit using fluid-solid coupled method, Advances in Mechanical Engineering, (2015)

15. Shubham Singh, Venkata Krishnan K., Spandana H., Mahesh Kumar N., P. S. Kulkarni, Numerical study of the heat transfer enhancement of circular tube bank fin heat exchanger with vortex generators, 20th Annual CFD Symposium - Bangalore, (2018)

16. R. Petkova-Slipets, K. Yordanov, P. Zlateva, A comparative thermal analysis of walls composed of traditional and alternative building materials, Civ. and Env. Eng. 16 (2), 388 (2020)

17. P. Zlateva, K. Yordanov, R. Petkova-Slipets, A study of the thermal properties of an alternative straw-containing building material, E3S Web of Conferences 207, 01004, PE-PM, (2020)

18. C. Oon, H. Togun, S. Kazi, A. Badarudin, M. Zubir, E. Sadeghinezhad, Numerical simulation of heat transfer to separation air flow in an annular pipe, Int. Commun. Heat Mass. J. 39, 1176 (2012)

19. E. Dimofte, F. Popescu, I. Ion, Numerical modelling of mixing fluids at different temperatures, Proceedings of TE-RE-RD, 35 (2016)

20. R. Petkova-Slipets, P. Zlateva, An analysis of the structure and thermal conductivity of hollow microsphere filled syntactic foams, Civ. and Env. Eng. 0 (0), (2019)

21. G. Popov, K. Klimentov, B. Kostov, R. Dimitrova, Determining the minor loss coefficient of cone diffusers, E3S Web of Conferences 207, PE-PM, 04004 (2020)

22. B. Gilev, N. Hinov, H. Ibrishimov, Mathematical model of induction heating with heat transfer of cylindrical body for pressing treatment. Proceedings of International Conference on High Technology for Sustainable Development HiTech, (2019)

23. N.L. Evstatieva, B.I. Evstatiev, Modelling of the thermal conditions of a LED driver, 26th International Symposium for Design and Technology in Electronic Packaging (SIITME), (2020)

24. P. Zlateva, K. Yordanov, Experimental study of heat pump type air-water for heating system performance, E3S Web of Conferences 112, 01007, TE-RE-RD, (2019) 